\title{
STUDIES OF THE PRINCIPLE IN LIVER EFFECTIVE IN PERNICIOUS ANEMIA. IV. THE THERAPEUTIC ACTIVITY OF ITS MULTIPLE FACTORS 1,2
}

\author{
BY BERNARD M. JACOBSON AND Y. SUBBAROW \\ (From the Medical Clinic, Massachusetts General Hospital, and the Department of Medicine \\ and Biochemical Laboratory, Harvard Medical School, Boston)
}

(Received for publication January 29, 1937)

Early in the course of an investigation of the principle in liver effective in pernicious anemia certain observations suggested the possibility that the therapeutic activity of liver extract might depend upon the presence of several chemically distinct substances. The evidence for this view was the fact that continued purification of therapeutically active liver extract, in the absence of significant losses and of destructive procedures, resulted in partial or complete extinction of therapeutic activity. On the other hand, the admixture with such highly purified materials of other fractions derived from liver extract resulted in the recovery of therapeutic activity. These latter fractions we have termed accessory factors, for they appeared to augment the activity of the primary factor (or factors), while in the absence of the primary factor they were therapeutically inert. This communication describes in detail the observations mentioned above, part of which have already been presented in a preliminary report (1).

\section{METHODS AND MATERIALS}

The patients studied were suffering from classical Addisonian pernicious anemia in relapse. Complications such as severe combined system disease and hemorrhage were absent. No infections occurred during the periods of observations, except for cystitis in three patients (Cases 7, 9, and 12, Table I). During the prolonged periods

\footnotetext{
1 Presented in part at the meeting of the American Society for Clinical Investigation, Atlantic City, May 6, 1935.

2 This investigation has been supported by Therapeutic Research Grants Numbers 244 and 267 of the Council on Pharmacy and Chemistry of the American Medical Association; by grants from the DeLamar Mobile Research Fund and the Proctor Fund of the Harvard Medical School, by a grant from the Ella Sachs Plotz Foundation, and by a grant from the William F. Milton Fund of Harvard University.
}

of study the patients' diet was of a mixed type, including meat or fish once daily, but devoid of yeast, liver, kidney, and tripe. Prior to the administration of therapeutically active fractions the blood level of each patient was established by adequate control periods, as noted in Table I.

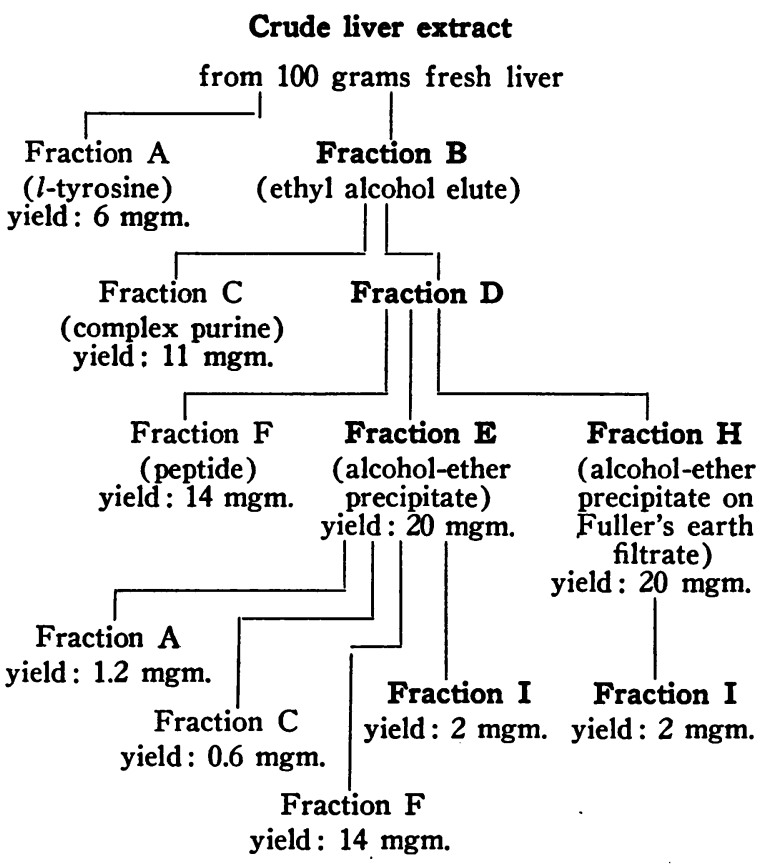

Fig. 1. Derivation of Purified Liver fractions

The percentage of reticulocytes in the capillary blood was estimated by the wet method, 1000 erythrocytes being counted. Erythrocyte, hemoglobin, and hematocrit determinations were made on venous blood drawn without stasis, and rendered incoagulable by heparin. The number of erythrocytes was determined with pipettes and counting-chambers certified by the Bureau of Standards. The volume' of packed red blood cells was measured in the Wintrobe hematocrit. The hemoglobin was determined by the Stadie-Wu method (12). The reticulocytes were counted 
TABLE I

Data of Figure 2

\begin{tabular}{|c|c|c|c|c|c|c|c|c|c|c|c|c|}
\hline \multirow{2}{*}{ 莺 } & \multirow{2}{*}{ 苞 } & \multirow{2}{*}{ 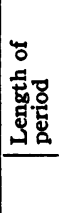 } & \multicolumn{2}{|c|}{ Date of period } & \multicolumn{5}{|c|}{ Fractions administered } & \multirow{2}{*}{$\begin{array}{l}\text { Calculated } \\
\text { amount of } \\
\text { primary } \\
\text { fraction } \\
\text { administered } \\
\text { per day }\end{array}$} & \multirow[t]{2}{*}{ Rate of administration } & \multirow{2}{*}{$\begin{array}{l}\text { Control } \\
\text { period } \\
\text { pre- } \\
\text { ceding } \\
\text { admin- } \\
\text { istration }\end{array}$} \\
\hline & & & & & $\mathbf{E}$ & $\mathbf{H}$ & $\mathbf{A}$ & C & $\mathbf{F}$ & & & \\
\hline & & days & & & \multicolumn{5}{|c|}{$\begin{array}{l}\text { total number grams } \\
\text { fresh liver from which } \\
\text { extract derived }\end{array}$} & $\begin{array}{l}\text { grams fresh liver } \\
\text { from which } \\
\text { extract derived }\end{array}$ & & days \\
\hline 1 & 1 & 20 & Dec. 18, & to Jan. 7,1936 & 200 & & 100 & 20 & & 10 & Every 2d day & 1 \\
\hline 2 & 2 & 30 & April 16 & to May 16,1936 & & 900 & 0 & 0 & 900 & 30 & Every 10th day & 2 \\
\hline 3 & 3 & 28 & April 17 & to May 15,1936 & & 300 & 300 & 300 & 0 & 11 & Every 10th day & $16 \ddagger$ \\
\hline 4 & 3 & 15 & April 2 & to April 17, 1936 & & 370 & $\mathbf{0}$ & 0 & 0 & 25 & Single & 1 \\
\hline 5 & 4 & 30 & Dec. 28, & to Jan. 27,1936 & 300 & & 110 & 200 & & 10 & Every 2d day & $10 \ddagger$ \\
\hline 6 & 4 & 9 & Dec. 19 & to Dec. 28,1935 & 100 & & 0 & 0 & & 11 & Every 2d day & 1 \\
\hline 7 & 5 & 14 & Mar. 20 & to April 3,1936 & & 100 & 0 & 0 & 100 & 7 & Single & 1 \\
\hline 8 & 1 & 20 & Feb. 5 & to Feb. 25,1936 & 200 & & $*$ & 200 & & 10 & Every 2d day & $50 \ddagger$ \\
\hline 9 & 6 & 18 & Dec. 9 & to Dec. 27, 1935 & 240 & & 0 & 0 & & 13 & Every 2d day & 10 \\
\hline 10 & 7 & 8 & April 30 & to May 8,1936 & & 100 & 100 & 100 & 100 & 13 & Single & 7 \\
\hline 11 & 4 & 10 & Jan. 27 & to Feb. 6,1936 & 100 & & 100 & 100 & & 10 & Every 2d day & $40 \ddagger$ \\
\hline 12 & 8 & 24 & Sept. 27 & to Oct. 21,1935 & 240 & & 240 & 240 & & 10 & Every 2d day & 3 \\
\hline 13 & 9 & 8 & May 1 & to May 9, 1936 & & 100 & 100 & 100 & 100 & 13 & Single & 11 \\
\hline 14 & 1 & 20 & Jan. 7 & to Jan. 27,1936 & 200 & & 300 & 200 & & 10 & Every 2d day & $21 \ddagger$ \\
\hline 15 & 10 & 10 & June 5 & to June 15,1936 & & 100 & 100 & 100 & 100 & 10 & Single & 75 \\
\hline 16 & 11 & 21 & Oct. 11 & to Nov. 1,1935 & 200 & & 200 & 200 & & 10 & Every 10th day & 6 \\
\hline 17 & 12 & 41 & Oct. 2 & to Nov. 12,1936 & & 600 & 600 & 600 & 600 & 15 & $\begin{array}{l}\text { Every } 2 \mathrm{~d} \text { day during } \\
\text { first } 20 \text { days, every } \\
10 \text { th day thereafter }\end{array}$ & 29 \\
\hline 18 & 13 & 14 & Oct. 25 & to Nov. 8,1935 & 100 & & 100 & 100 & & 7 & Single & 22 \\
\hline 19 & 2 & 27 & May 16 & to June 12,1936 & & 300 & 300 & 300 & 300 & 11 & Every 10th day & $32 \ddagger$ \\
\hline 20 & 1 & 16 & Feb. 25 & to Mar. 12,1936 & 100 & & 100 & 100 & & 6 & $\begin{array}{l}\text { Every } 2 \text { d day during } \\
\text { first } 8 \text { days }\end{array}$ & $70 \$$ \\
\hline 21 & 1 & 16 & Mar. 23 & to April 8,1936 & 100 & & $t$ & 100 & & 6 & $\begin{array}{l}\text { Every } 2 \mathrm{~d} \text { day during } \\
\text { first } 8 \text { days }\end{array}$ & $97 \ddagger$ \\
\hline 22 & 6 & 12 & Dec. 27, & to Jan. 8,1936 & 170 & & 170 & 170 & & 14 & Every 2d day & $28 t$ \\
\hline
\end{tabular}

* $100 \mathrm{mgm}$. Fraction A orally daily.

† 1.0 gram Fraction A orally daily.

† Includes preceding experimental period. 
daily and the venous blood constituents were studied, in most cases, on alternate days.

The derivation from commercial liver extract (Fraction G of Cohn et al. (2)) of the materials discussed in this communication is presented in Figure 1. In this figure the fractions containing the primary factor are depicted by heavy type. They are Fractions B, D, E, H, and I. The details of the preparation of Fractions A, B, and C have been previously described $(3,4)$. From Fraction $\mathrm{D}$ the primary factor has been brought down in both of the amorphous fractions $E$ and H. From Fraction D, also, was separated Fraction $F$ (an accessory factor) by precipitation with rhodanilic acid (5). The sources of primary factor discussed in this communication are Fraction $\mathrm{E}$ and Fraction $\mathrm{H}$. While Fraction $\mathrm{E}$ contains both primary factor and Fraction $F$, as well as very small amounts of Fractions $A$ and $C$, Fraction $\mathrm{H}$, although amorphous, is completely devoid of Fractions A, C, or F. Fraction I was obtained from either Fraction $\mathrm{E}$ or from Fraction $\mathrm{H}$, by precipitation with Reinecke salt and subsequent regeneration, as a microcrystalline sulfate in a yield of $2 \mathrm{mgm}$. from 100 grams of fresh liver (6). Studies of the therapeutic action of Fraction I will be presented in a later communication.

The accessory factors are represented by Fractions $\mathrm{A}, \mathrm{C}$, and $\mathrm{F}$. Fraction $\mathrm{A}$, obtained in a yield of $6 \mathrm{mgm}$. from 100 grams of liver, has been identified as $l$-tyrosine (3). In most of the experiments recorded below crystalline commercial $l$-tyrosine (Kahlbaum or Eastman Kodak) has been employed instead of Fraction $\mathrm{A}$ isolated from liver. Fraction C, obtained in a yield of 11 mgm. from 100 grams of liver, has been identified as a complex purine (3) and was administered in a crystalline state. Fraction F, a peptide, was prepared either directly from Fraction $D$ or from Fraction $E$, in a yield of $14 \mathrm{mgm}$. from 100 grams of liver (5), and has been administered as a regenerated crystalline rhodanilate.

Throughout the experiments recorded below Fractions E (with the exception of the material administered to Patient 10, Table $I$ ) and $H$ have been obtained from the same original supply of each fraction prepared in a large amount. The following quantities of the various fractions have been administered, as derived from 100 grams of fresh liver: Fraction A, $11 \mathrm{mgm}$.; Fraction C, 6 mgm.; Fraction 'F, 14 mgm.; Fraction E, 20 mgm.; and Fraction H, 20 mgm.

Unless otherwise noted, all of the fractions were sterilized by boiling for one minute on the weakly acid side (alkaline to methyl red and acid to phenol red), and were administered by intramuscular injection.

\section{The therapeutic activity of the primary factor, with and without the accessory factors}

The therapeutic activity of the primary factor without ${ }^{3}$ the three accessory factors, administered as either Fraction $\mathrm{E}$ or $\mathrm{H}$, was studied in six patients during nine periods of observation. These fractions were administered during periods varying from nine to thirty days in length, in amounts derived from 7 to 30 grams of liver per day. The effects of these fractions upon erythrocyte production are depicted in the left-hand part of Figure 2. The primary factor as either Fraction $\mathrm{E}$ or $\mathrm{H}$, together with the three accessory factors, was administered to eleven patients during thirteen periods of observation from eight to forty-one days in length, in amounts derived from 6 to 15 grams of liver per day. Included among these latter patients were four to whom had been previously administered primary factor without the accessory factors. In the right-hand part of Figure 2 are depicted the individual erythrocyte regeneration curves following the administration of the primary factor together with the three accessory factors. The fractions administered, the amounts, and other relevant data bearing upon these erythrocyte regeneration curves are noted in Table $I$.

It is evident from inspection of Figure 2 that, in the absence of the three accessory factors, the effect of either Fraction $\mathrm{E}$ or $\mathrm{H}$ upon erythrocyte production (with the exception of Curve 2 ; vide infra) was either slight and of short duration (Curves $1,3,4,7,9$ ), or was entirely lacking (Curves 5, 6, 8). On the other hand, after the administration of the primary factor together with Fractions $\mathrm{A}, \mathrm{C}$, and $\mathrm{F}$, the erythrocyte responses showed a high degree of activity.

3 Although Fraction $\mathrm{E}$ contains Fraction $\mathrm{F}$, and very small quantities of Fractions $A$ and $C$ (Figure 1), for the purpose of the present discussion it is considered in conjunction with Fraction $\mathrm{H}$. Fraction $\mathrm{H}$ is completely devoid of Fractions A, C, and F. 


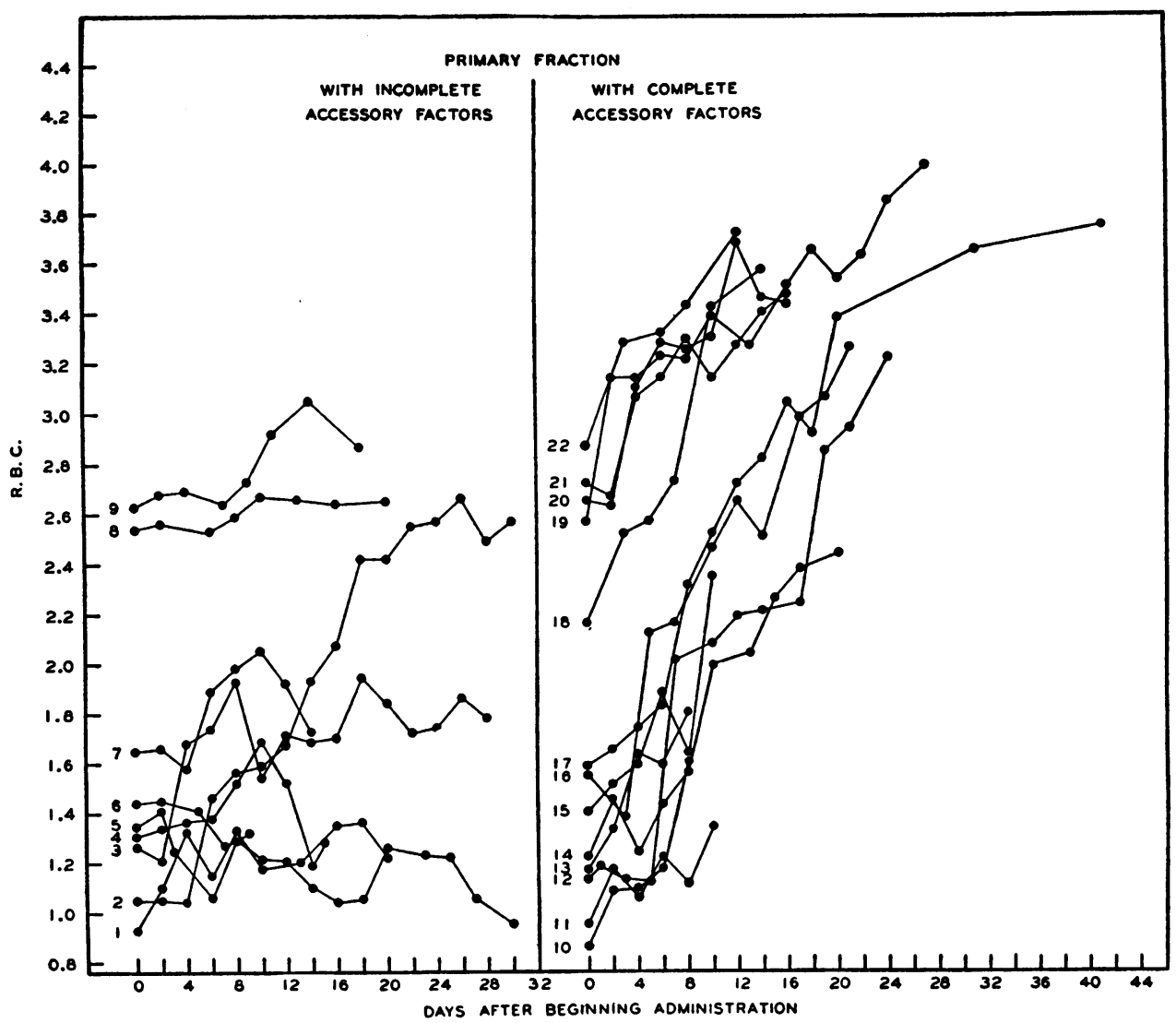

Fig. 2. Erythrocyte Regeneration Curves following the Administration of Primary Factor with Incomplete and with Complete Accessory Factors. Fractions administered, Quantities, and Other Data Contained in Table I

TABLE II Comparative reticulocyte responses to primary factor with and without accessory factors

\begin{tabular}{|c|c|c|c|c|c|c|c|c|c|c|}
\hline \multirow[b]{2}{*}{ Fraction $\ldots \ldots \ldots \ldots \ldots \ldots \ldots \ldots \ldots$} & \multicolumn{6}{|c|}{ Primary factor with incomplete accessory factors } & \multicolumn{4}{|c|}{$\begin{array}{l}\text { Primary factor with complete } \\
\text { accessory factors }\end{array}$} \\
\hline & $\mathbf{E}$ & $\mathbf{H}$ & $\mathbf{H}$ & $\mathbf{E}$ & $\mathbf{H}$ & $\mathbf{E}$ & $\mathbf{H}$ & $\mathbf{E}$ & $\mathbf{E}$ & $\mathbf{H}$ \\
\hline Patient......................... & 1 & 2 & 3 & 4 & 5 & 6 & 7 & 8 & 11 & 12 \\
\hline Curve number in Figure $2 \ldots \ldots \ldots \ldots$ & 1 & 2 & 4 & 5 & 7 & 9 & 10 & 12 & 16 & 17 \\
\hline $\begin{array}{l}\text { Total amount fresh liver from which } \\
\text { extract derived, grams.............. }\end{array}$ & 100 & 300 & 370 & 100 & 100 & 200 & 100 & 100 & 100 & 200 \\
\hline R.B.C. at beginning, millions per cu. $\mathrm{mm}$. & 0.93 & 1.05 & 1.32 & 1.44 & 1.65 & 2.62 & 0.86 & 1.15 & 1.56 & 1.57 \\
\hline R.B.C. at end, millions per cu. mm..... & 1.19 & 1.58 & 1.69 & 1.32 & 2.05 & 2.73 & 1.60 & 2.08 & 2.46 & 2.52 \\
\hline Reticulocytes at peak, per cent........ & 7.8 & 31.0 & 16.4 & 3.0 & 9.8 & 4.4 & 24.6 & 25.0 & 23.8 & 18.1 \\
\hline
\end{tabular}

* The abbreviation -20 stands for "derived from 20 grams of liver." 
All of the curves of Figure 2 are represented in the average erythrocyte regeneration curves of Figure 3. To facilitate interpretation the curves representing initial erythrocyte levels below 2.0 million have been averaged separately from those representing initial levels above 2.0 million. It is evident that the administration of the primary factor, together with Fractions A, C, and F, resulted in a rate of erythrocyte regeneration markedly greater than that produced by the primary factor in the absence of all three of the accessory factors, despite the administration, in the latter instance, of considerably larger quantities of pri- mary factor. Indeed, the administration of both primary and accessory factors resulted in a rate of erythrocyte production closely approximating that induced by the intramuscular administration of an identical average daily dosage (derived from 11 grams of liver) of a commercial liver extract recently studied by Murphy (7).

Data concerning reticulocyte production following the administration of the primary factor alone were obtained in six patients, whose initial erythrocyte levels permitted a possible reticulocyte response. These observations are presented in Table II. For comparison there are included the

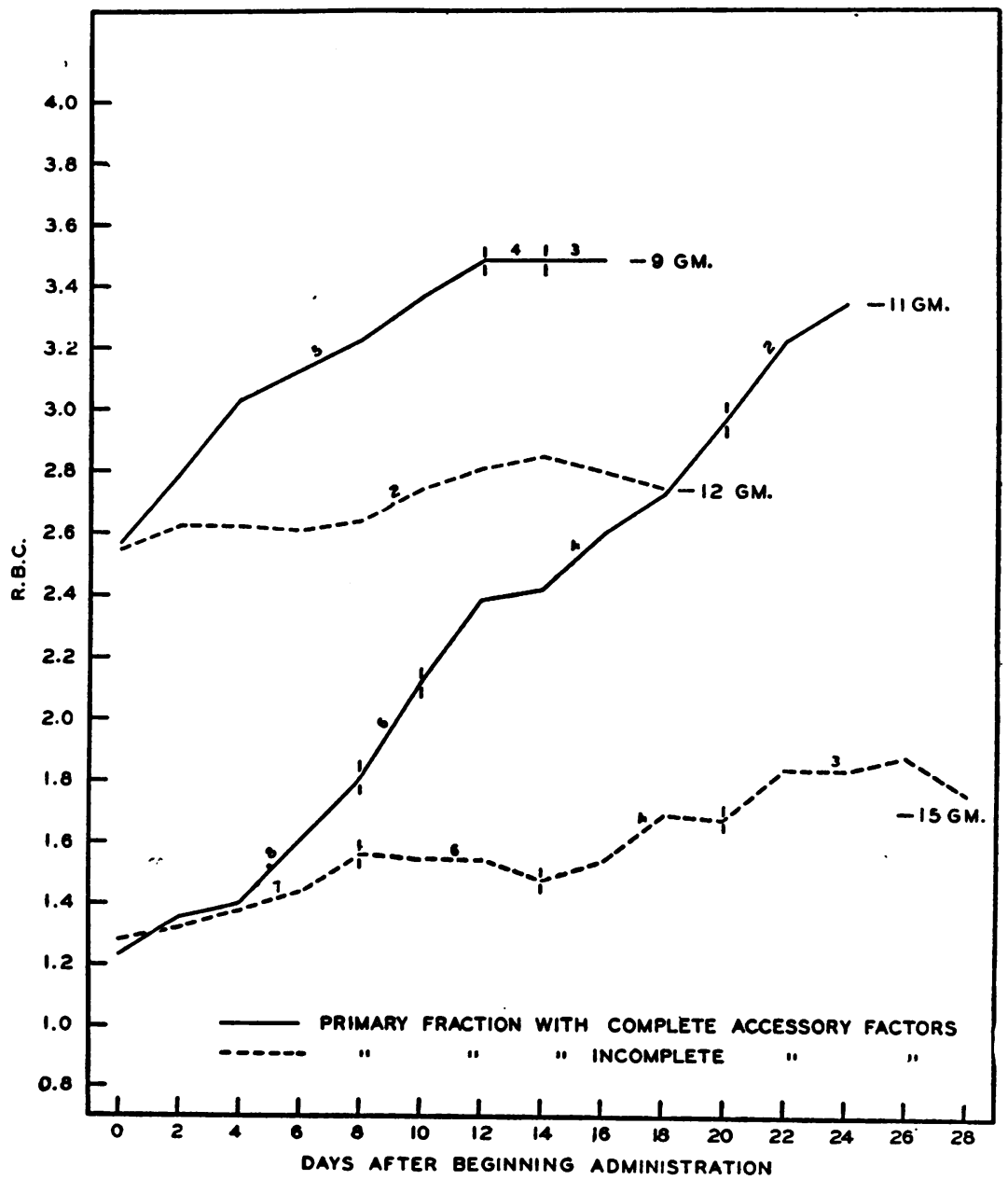

Fig. 3. Averages of All Erythrocyte Regeneration Curves Contained in Figure 1, at Two Different Initial Erythrocyte Levels

The number of separate experiments included in each average is represented by the numerals directly above each curve; the periods corresponding to these numerals are defined by the small vertical lines. The quantity at the end of each curve denotes the calculated average daily amount, in terms of fresh liver from which the extract was derived, of primary fraction administered. 


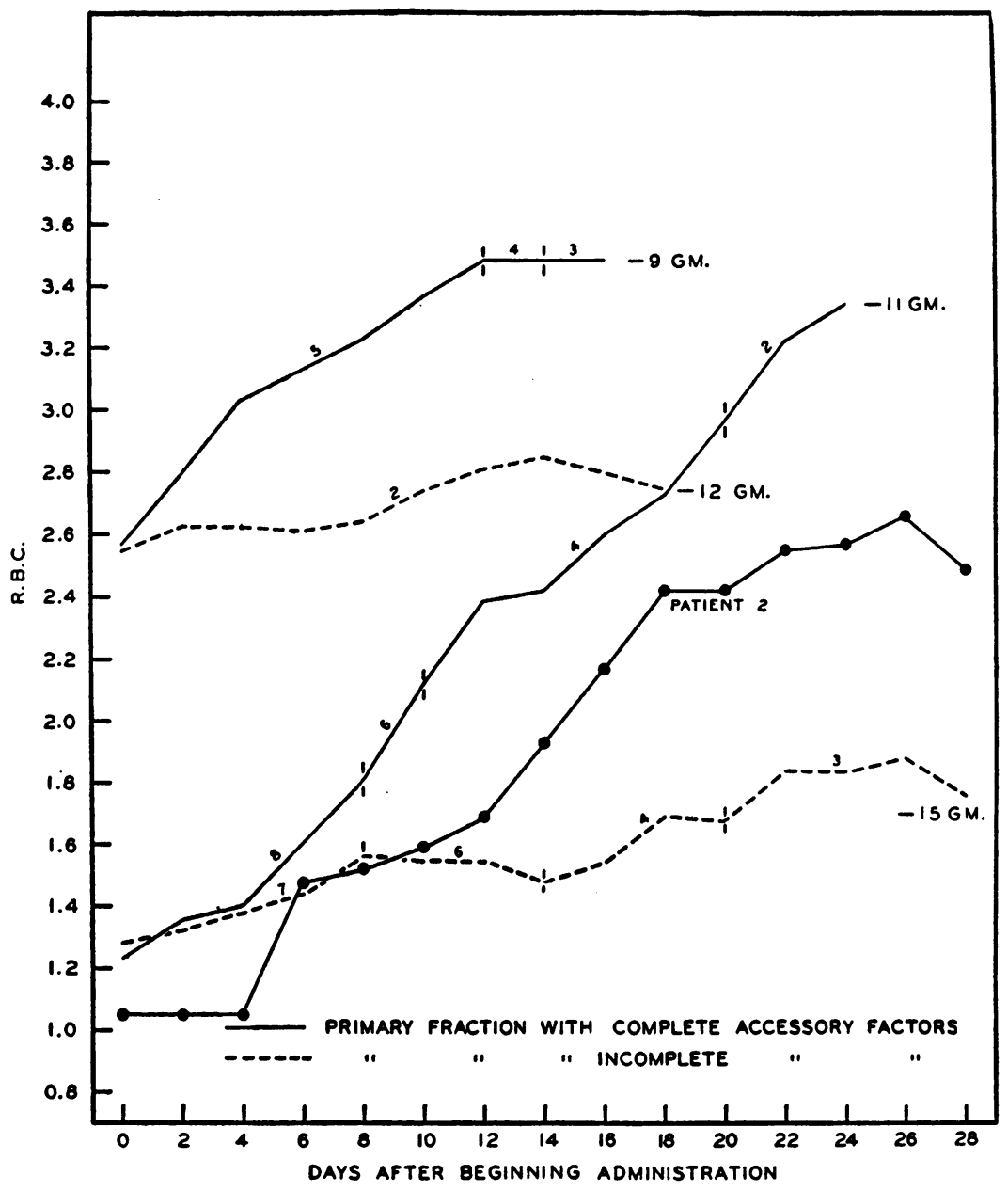

Fig. 4. Erythrocyte Response to Administration of Massive Amount (- 300 Grams Every Tenth Day) of Primary Factor with Incomplete Accessory Factors (Patient 2)

This erythrocyte regeneration curve is superimposed on the curves of Figure 3 , for comparison with average response to administration of smaller amount of primary factor together with complete accessory factors. See text.

predicted reticulocyte peaks, based upon unpublished data of the authors, following the intramuscular injection of commercial liver extract derived from 100 grams of liver. It is evident that Fraction $\mathrm{E}$ or Fraction $\mathrm{H}$, when administered in an amount derived from 100 or 200 grams of liver, during the first ten days, induced markedly submaximal reticulocyte responses, regardless of the rate of administration (single dose in Patient 5, divided doses in Patients 1, 4, and 6). After the administration of a massive amount of Fraction $\mathrm{H}$ (derived from 300 grams of liver) a maximal response followed in Patient 2, but an even larger amount (derived from 370 grams of liver) administered to Patient 3 was followed by a submaximal response. On the other hand, in four patients treated with moderate amounts of Fractions $\mathrm{E}$ or $\mathrm{H}$, together with the three accessory factors, the reticulocyte responses were approximately maximal. (See Table II.)

The effects of massive amounts of the primary factor with incomplete accessory factors

The therapeutic effects of large amounts of the primary factor alone were studied during a prolonged period in one patient. The erythrocyte 
regeneration curve of this case (Patient 2) is included in Figure 2 (Curve 2), and is also presented in Figure 4, in order to facilitate comparison with the average erythrocyte regeneration curves of Figure 2. To this patient (Figure 4) at an initial erythrocyte level of 1.05 million, were administered Fractions $\mathrm{H}$ and $\mathrm{F}$, each derived from $\mathbf{3 0 0}$ grams of liver, in a single dose. The same amount of each fraction was again administered on the tenth and on the twentieth days, totaling material derived from 900 grams of liver during thirty days. The reticulocyte response was maximal, reaching a peak of 31.0 per cent on the sixth day. During the first ten days the erythrocytes rose to 1.58 million, by the thirtieth day they reached a level of 2.5 million. It is apparent, from the data of Figure 4, that the erythrocyte response to the administration of large amounts ( -30 grams per day) ${ }^{4}$ of the primary factor, without the three accessory factors, was not as great as the average erythrocyte response to smaller amounts ( -11 grams per day) of primary factor together with the accessory factors. At the end of this period Fractions H, A, C, and $F$, each derived from 100 grams of liver, were administered to this patient, and the same dosage was repeated on the tenth and on the twentieth days. The erythrocytes continued to rise, reaching a count of 4.0 million on the twenty-seventh day (Curve 19, Figure 2).

\section{The augmentative action of each accessory factor}

In the studies described above all three of the accessory factors, Fractions $\mathrm{A}, \mathrm{C}$, and F, were administered together with the primary factor (Fraction $\mathrm{E}$ or $\mathrm{H}$ ). That each of these fractions may act as an accessory factor was suggested by certain indirect evidence (1). Direct evidence for this view was furnished by the following observations.

The administration of an adequate amount of primary factor together with Fractions $\mathrm{C}$ and $\mathrm{F}$, but with an incomplete amount of Fraction A, was followed, in two patients, by no erythrocyte response. To Patient 4 (Curve 5, Figure 2), at an initial erythrocyte level of 1.3 million, were administered on alternate days Fractions E - 20

\footnotetext{
4 The abbreviation -30 grams per day stands for "derived from 30 grams of liver per day."
}

grams (derived from 20 grams of fresh liver), $\mathrm{C}-10$ grams, and $\mathrm{A}-2$ grams, during the first ten days; during the second ten days the dosage on alternate days was $\mathrm{E}-20$ grams, C -10 grams, and $\mathrm{A}-10$ grams; and during the last ten days, $\mathrm{E}-20$ grams, $\mathrm{C}-20$ grams, and A - 10 grams. It is seen that even after the increase of Fraction $C$, in the absence of a complete amount of Fraction A, during the last ten days, the erythrocytes continued to fall, reaching 0.95 million. To the patient were then administered on alternate days doses of Fractions $E-20$ grams, C -20 grams, and A -20 grams, during the following ten days, and, as depicted in Curve 11 , Figure 2, the erythrocytes rose to 1.34 million, accompanied by clinical improvement. Similar observations were made in Patient 1 , at an initial erythrocyte level of 2.54 million. As shown in Figure 6, to this patient were administered on alternate days doses, during a period of twenty days, of Fractions $E-20$ grams and $C-20$ grams, as well as $100 \mathrm{mgm}$. of tyrosine (Fraction A), orally, daily. The erythrocytes remained stationary. In the next succeeding period the same amounts of Fractions $\mathrm{E}$ and $\mathrm{C}$ were continued, but Fraction A -20 grams, was administered on alternate days by intramuscular injection. A satisfactory erythrocyte response promptly followed.

The accessory action of Fraction $\mathrm{C}$, in the presence of an adequate amount of the other factors, was suggested by the following observations upon Patient 1, presented in Figure 5. During these observations over a period of forty days Fraction $\mathrm{E}-20$ grams was administered on alternate days. During the first twenty days Fraction $\mathrm{C}-2$ grams was also administered at the same rate. During the first ten days no additional Fraction A was injected (other than that contained in Fraction E; see Figure 1). It is seen that during this first period the reticulocytes rose to a peak of 9.2 per cent on the eighth day, followed by a rise of erythrocytes from 0.92 million to 1.2 million. Slight clinical improvement took place. During the second period of ten days, Fraction $\mathrm{A}-20$ grams, administered on alternate days, was added to the previous dosage of Fractions $\mathrm{E}$ and $\mathrm{C}$. In response to these materials the reticulocytes did not continue to fall, but rose again to a peak of 9 


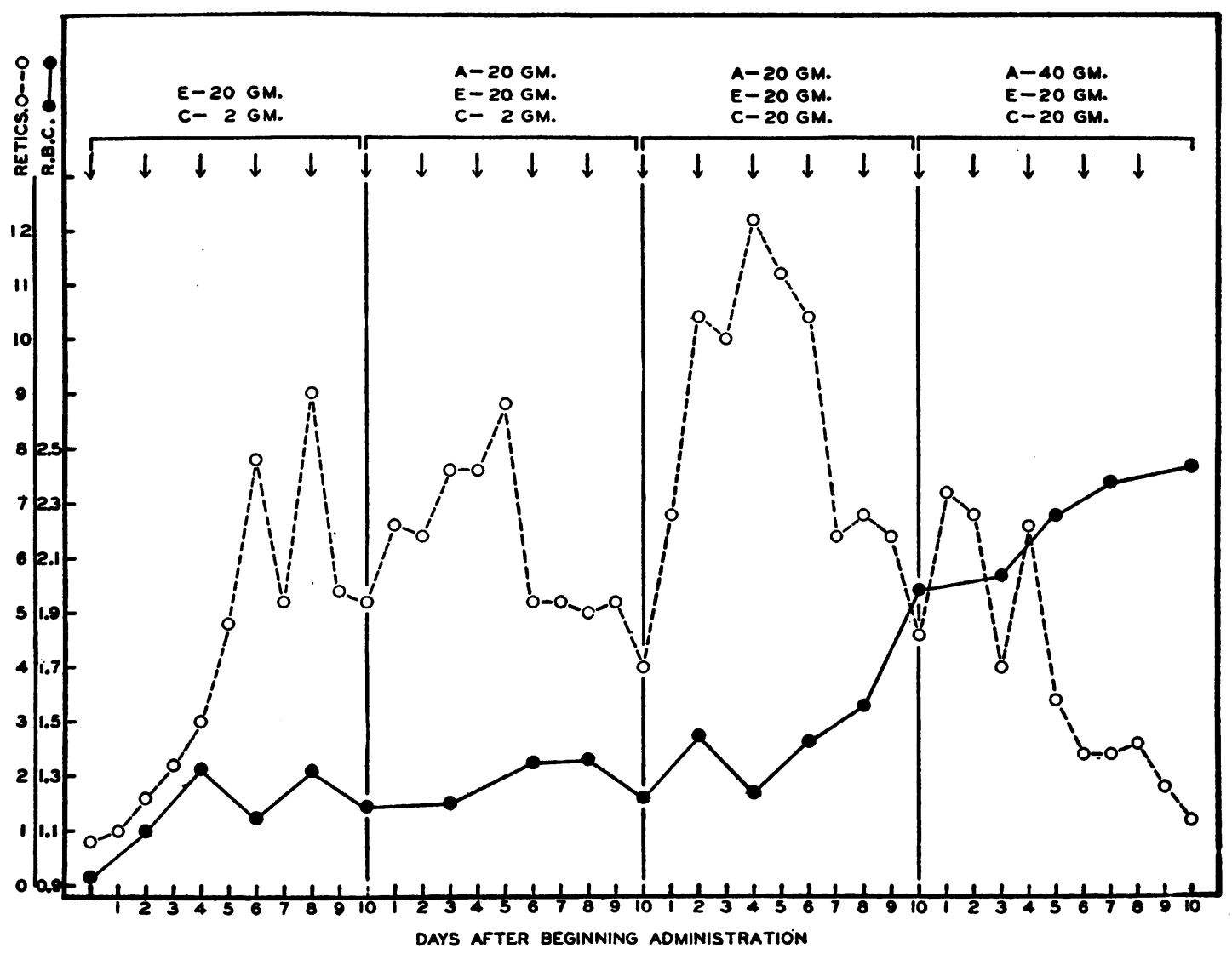

Fig. 5. Patient 1. Fraction C as an Accessory Hematopoietic Factor

The quantities above each period refer to the amounts of fractions injected on the days denoted by each arrow. Throughout the four periods Fraction E -20 grams was administered on alternate days. During the first two periods Fraction $\mathrm{C}-2$ grams was administered on alternate days. There were only slight reticulocyte and erythrocyte responses in the first period in the absence of Fraction $A$ and no further erythrocyte rise in the second period after addition of Fraction A -20 grams on alternate days. The increase of Fraction $\mathrm{C}$ to -20 grams in the third period resulted in the greatest rise of reticulocytes and satisfactory rise of erythrocytes, continuing in the fourth period.

per cent; the erythrocytes remained stationary, and the clinical condition was unchanged. During the third period the dosage of Fraction $\mathrm{C}$ on alternate days was increased from -2 to -20 grams, while the same amounts of Fractions E and $\mathrm{A}$ were continued. $\mathrm{A}$ third and distinctly orderly reticulocyte response, with a maximum of 12.4 per cent on the fourth day, was induced, and the erythrocytes rose from a level of 1.2 million to one of 2.0 million. Marked clinical improvement accompanied the changes in the blood. During the fourth period of ten days the continued administration on alternate days of the same fractions, except for an increase of the dosage of Fraction A from -20 to -40 grams, was ac- companied by a continued rise of the erythrocytes. Thus the continuous administration of primary factor, as Fraction E, together with Fraction A, but with minimal amounts of Fraction $C$, induced only slight reticulocyte and erythrocyte responses. A ten-fold increase in the amount of Fraction $\mathrm{C}$ (third period, Figure 5), however, was followed by a reticulocyte response of greater magnitude, and by a satisfactory gain of erythrocytes. That Fractions E, A, and C, each derived from 20 grams of liver, were therapeutically more effective than Fractions $E-20, A-20$, and $C-2$, is suggested in view of the discussion of double reticulocyte responses by Minot and Castle (8).

The accessory action of Fraction $F$, in the 
presence of the primary factor together with Fractions $\mathrm{A}$ and $\mathrm{C}$, was indicated by the following observations. To Patient 3 (Curve 4, Figure 2) at an 'initial erythrocyte level of 1.3 million was administered a single dose of Fraction $\mathrm{H}-370$ grams. (It is to be recalled that Fraction $\mathrm{H}$, in contrast with Fraction $\mathrm{E}$, is completely devoid of Fractions A, C, and F.) During the following fifteen days the erythrocytes rose slightly but then receded to a final value of 1.28 million. During the succeeding twenty-eight days (Curve 3 , Figure 2), to Fraction $\mathrm{H}-100$ grams were added Fractions $\mathrm{A}-100$ grams and $\mathrm{C}-100$ grams. These amounts were administered every tenth day. On the seventh day the reticulocytes rose to a peak of 24.4 per cent, followed by a rise of the erythrocytes to 1.93 million on the eighth day. Thereafter, the erythrocytes rose no further, and by the twenty-eighth day had declined to 1.78 million. At this point commercial liver extract was administered, followed by rapid rise of the erythrocytes. Thus, in the complete absence of Fraction F, Fractions $H, A$, and $C$ induced a rise of erythrocytes of only 0.5 million during a period of twenty-eight days. On the other hand, after the addition of Fraction $\mathrm{F}$, Fractions $\mathrm{H}, \mathrm{A}$, and $\mathrm{C}$, administered in similar dosage, induced satisfactory erythrocyte responses in five other patients (Curves 10,13,15, 17, and 19, Figure 2).

\section{The inactivity of the accessory factors in the $a b$ - sence of the primary factor}

In Table III are presented data concerning the negative therapeutic activity of the three accessory factors, Fractions A, C, and F, in the absence of the primary factor. After the administration of the stated amounts of accessory factors in a single dose observations of the reticulocytes and of the erythrocytes were made during periods ranging from seven to twenty days. In subsequent periods either commercial liver extract, or partially purified experimental liver extract, was administered, with resulting satisfactory responses in each case. It is seen that neither Fractions A, $\mathrm{C}$, or $\mathrm{F}$ individually or together (Patients 10 , 20 , and 21, Table III) induced significant rises of reticulocytes or erythrocyte responses, in patients who subsequently reacted to the administration of crude liver extracts.
Parenterally contrasted with orally administered tyrosine as an accessory factor

The experimental evidence discussed above, that as little as $6 \mathrm{mgm}$. of $l$-tyrosine (Fraction A - 100 grams liver), when administered by intramuscular injection, acted as an accessory factor, is difficult to reconcile with the apparent fact that the patients who formed the subjects of this investigation derived several grams of tyrosine daily from ingested protein. The patients consumed a normal amount of protein, severe diarrhea was absent, no gross evidence of defective protein digestion was manifest, and during the experimental periods most of the patients gained in weight.

In the hope of throwing some light on this problem the following study was undertaken. Patient 1, following the observations recorded in Figure 5 , remained without treatment for one week, during which the erythrocyte level 'remained stable. The experiment presented in Figure 6 was then instituted. During the first period of twenty days Fractions $\mathrm{E}-20$ grams and $\mathrm{C}-20$ grams were administered on alternate days. During this period also $100 \mathrm{mgm}$. of commercial $l$-tyrosine was administered orally every day. No change in the patient's clinical condition took place, and during the twenty days the erythrocytes rose from 2.55 million to only 2.65 million. During the first ten days of the following period the administration on alternate days of the same basic fractions, $\mathrm{E}$ -20 grams and $\mathrm{C}-20$ grams, was continued, but only $1.2 \mathrm{mgm}$. of tyrosine (A -20 grams) was injected intramuscularly on alternate days. However, a sharp rise of the erythrocytes to 3.48 million in sixteen days ensued, accompanied by clinical improvement.

During the nineteen days following the last treatment the erythrocytes declined to 2.72 million. At this point the same basic fractions $\mathrm{E}$ -20 grams and $\mathrm{C}-20$ grams were administered, and continued on alternate days for ten days. During this period 1.0 gram of tyrosine was ingested daily. An erythrocyte response promptly followed, reaching in sixteen days 3.48 million. It is evident that the slope of the erythrocyte curve following the daily oral administration of 1.0 gram of tyrosine is very similar to that following the parenteral administration on alternate days of $1.2 \mathrm{mgm}$. of tyrosine. 
BERNARD M. JACOBSON AND Y. SUBBAROW

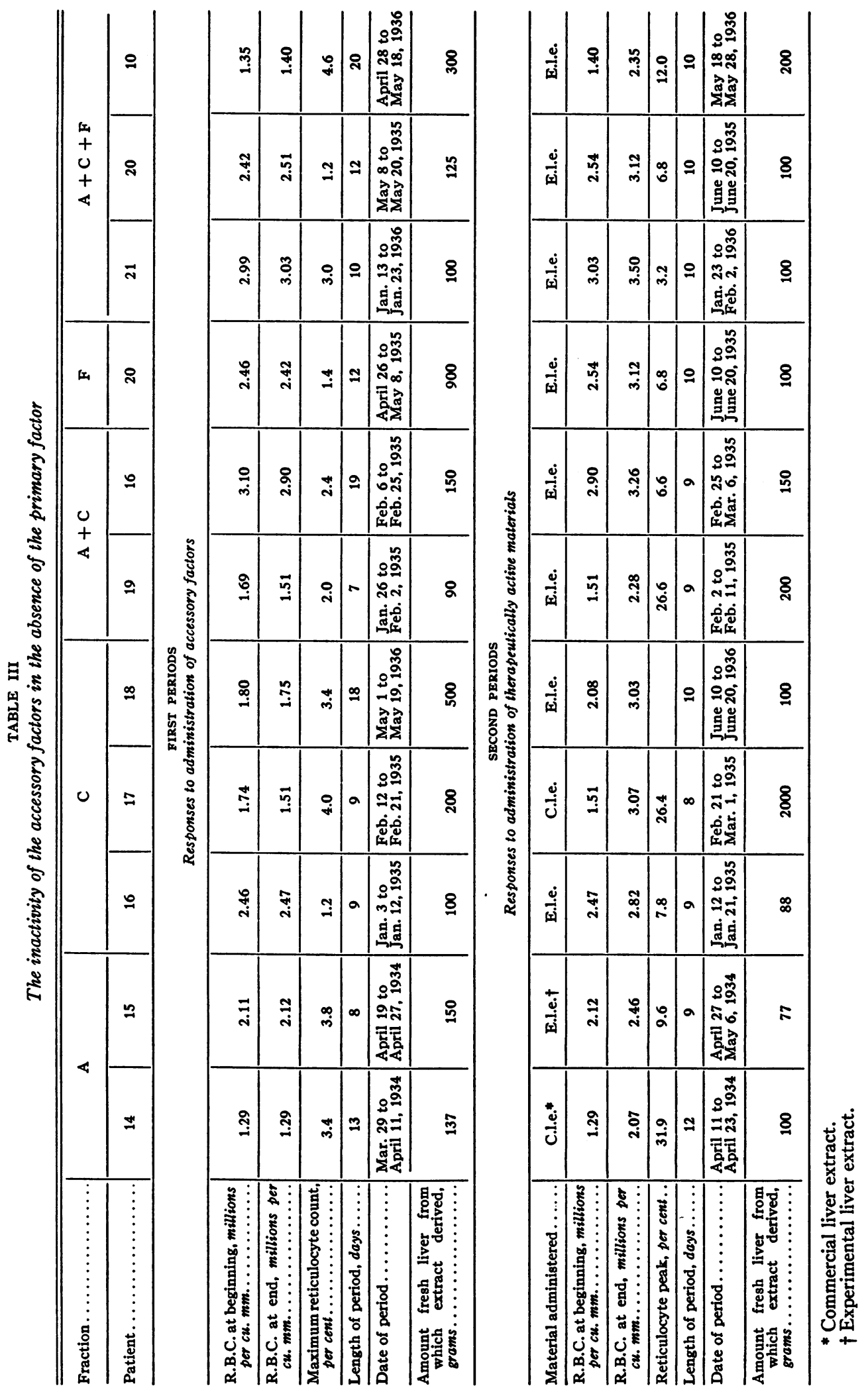




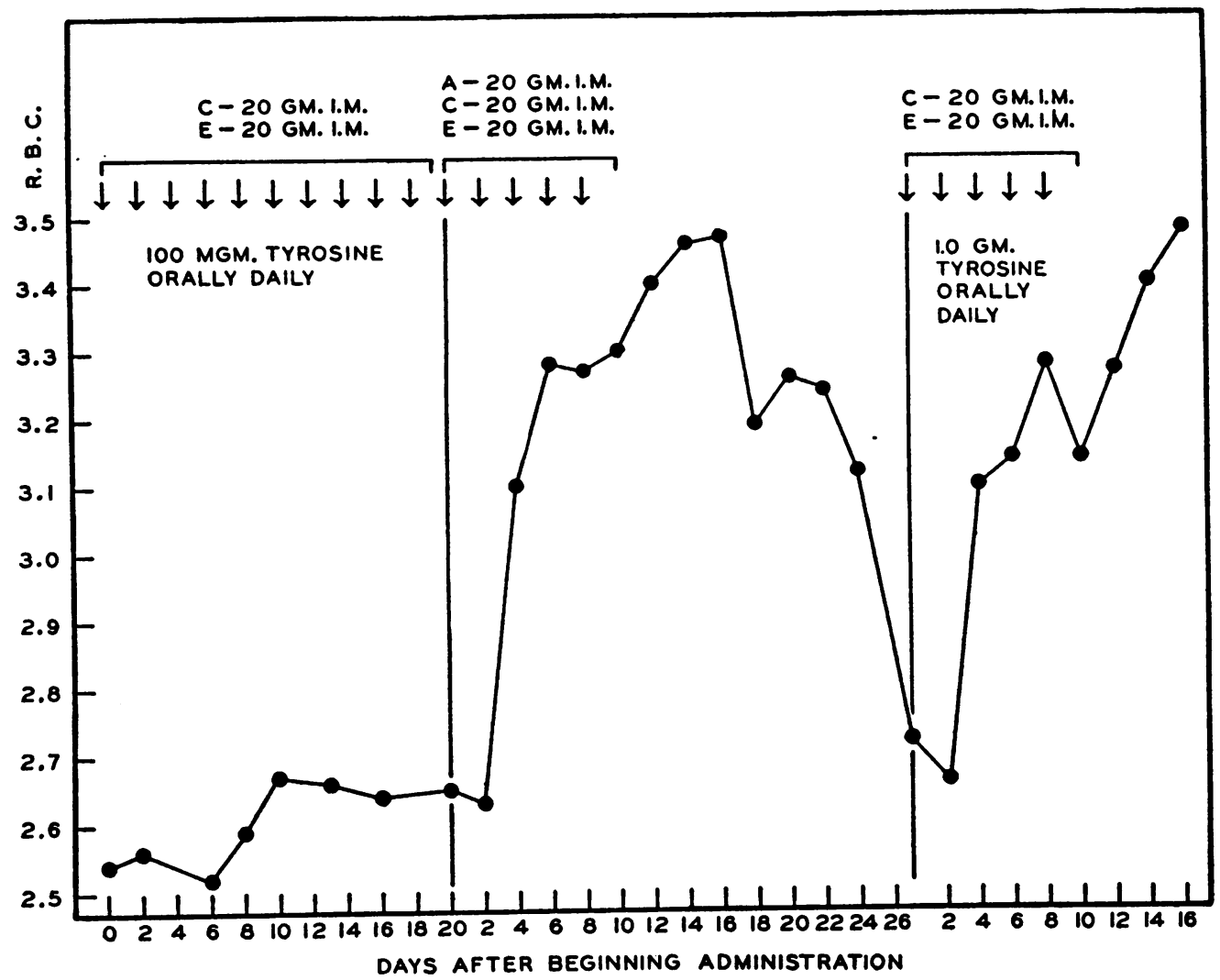

Fig. 6. Patient 1. Parenterally Contrasted with Orally Administered Tyrosine (Fraction A) as an ACcessory Hematoporetic Factor

The quantities above each period refer to the amounts of fractions injected on the days denoted by each arrow. Fractions $\mathrm{E}$ and $\mathrm{C}$ were injected at a uniform rate in each of three periods. There was no erythrocyte response during the first period of twenty days while $100 \mathrm{mgm}$. of tyrosine was administered orally daily, followed by satisfactory rise of erythrocytes in the second period after $1.2 \mathrm{mgm}$. tyrosine was injected on alternate days. Following cessation of treatment, erythrocytes declined to previous level. In the third period, there was another satisfactory erythrocyte response after daily oral administration of 1.0 gram tyrosine.

It is thus suggested by these data that in this particular patient, at least, $100 \mathrm{mgm}$. of tyrosine ingested daily in addition to the tyrosine derived from the diet, was not equivalent in accessory hematopoietic activity to $0.6 \mathrm{mgm}$. (per day) of parenterally administered tyrosine, while a tenfold increase of the orally administered tyrosine was as active as the injected tyrosine.

\section{DISCUSSION}

The observations described above suggest that the complete therapeutic action of relatively crude liver extract in pernicious anemia was induced only by the presence in the extract of several chemically distinct substances. The evidence for this hypothesis has been derived partly from data concerning reticulocyte production, but principally from data concerning erythrocyte regeneration during prolonged periods. One fraction has been termed a primary factor, the other fractions accessory factors. The primary factor alone, when administered in an amorphous impure state (Fractions $\mathrm{E}$ or $\mathrm{H}$ ), exerted at most only a moderate therapeutic effect. The accessory factors (Fractions $\mathrm{A}, \mathrm{C}$, and F) were individually and collectively completely inert. On the other hand, the administration of the primary factor together with the three accessory factors was followed by satisfactory clinical improvement and by a rapid rate of erythrocyte regeneration. 
It might be assumed that the satisfactory therapeutic activity of the four fractions together depended upon additive effects of a substance common to all. That this is unlikely is evidenced by the data of Table III. Fractions A, C, and F were individually and collectively administered in amounts sufficiently great, so that had there been contamination with the primary factor a response would have occurred. All of the evidence, rather, suggests that Fractions $\mathrm{A}, \mathrm{C}$, and $\mathrm{F}$ augmented the activity of a primary factor. Furthermore, it might be assumed that the entire therapeutic activity of liver extract resides in a single substance, and that the inadequate effects of our primary factor were due to the administration of insufficient amounts. Against this interpretation is the fact that even after the administration of an amount of primary factor derived from as much as 30 grams of liver per day (Curves 2 and 4, Figure 2), instead of the usual dosage of extract derived from 10 grams of liver per day, the resulting clinical and hematopoietic effects were inferior to those that followed the administration of smaller amounts ( -10 grams) of primary factor, together with like amounts of the three accessory factors.

We do not possess evidence that all possible accessory factors in crude liver extract are represented by Fractions A, C, and F. Nor do the present experimental data permit the conclusion that the four factors described are sufficient to induce a complete clinical and hematopoietic remission, and to maintain such a remission over a prolonged period. The longest periods over which continued observations have been made are the following. Patient 2, treated with Fractions $\mathrm{H}, \mathrm{A}, \mathrm{C}$, and $\mathrm{F}$, reached an erythrocyte level of 4.0 million in 27 days (Curve 19, Figure 2). $\mathrm{Pa}$ tient 12, whose course is depicted in Figure 2 (Curve 17), was treated with Fractions H, A, C, and $F$; at the end of 60 days the erythrocytes numbered 4.46 million.

Observations in one patient presented above have indicated that the accessory hematopoietic action of $l$-tyrosine (Fraction A), parenterally administered in an amount no greater than $0.6 \mathrm{mgm}$. per day, surpassed that effected by the tyrosine presumably derived from ingested protein, together with a daily oral ration of $100 \mathrm{mgm}$. of $l$-tyrosine. These contrasting effective dosages might be due to either defective absorption of orally administered tyrosine, to abnormal destruction of tyrosine in the intestine, or to an abnormality of utilization of absorbed tyrosine. No data are at hand which bear on these possibilities.

The minimal quantities of all four factors that induce a satisfactory response have not been determined. With Fraction $\mathrm{E}$ as the primary factor the smallest total dosage administered was 26 mgm. of solids per 10 days (Figure 2, Curve 18). With Fraction $\mathrm{H}$ as the primary factor the smallest dosage administered was $51 \mathrm{mgm}$. of solids, per 10 days (Figure 2, Curve 15).

The above quantities are of interest in relation to the purified liver extracts recently described by other workers. Very similar amounts of total solids (per 10 days), with resulting satisfactory initial erythrocyte gains, were administered by Dakin, Ungley and West (9). On the other hand, Strandell, Poulsson and Schartum-Hansen (10) have recently reported hematopoietic responses following the use of purified amorphous material consisting of $0.35 \mathrm{mgm}$. of solids derived from 100 grams of liver, material that was prepared by Laland and Klem (11). Strandell and his collaborators administered this material to four patients, in the following dosages: Case I, total of $2.1 \mathrm{mgm}$. over a period of 42 days; Case II, $2.1 \mathrm{mgm}$. over a period of 32 days; Case III, $0.7 \mathrm{mgm}$. over a period of 9 days; and, Case IV, $0.7 \mathrm{mgm}$. over a period of 10 days. Although these authors conclude that $0.7 \mathrm{mgm}$. of their material "has a very good antianemic effect" their data, in our opinion, do not entirely substantiate this conclusion. Thus in Case I, although no initial erythrocyte count is given, on the seventh day the erythrocytes numbered 1.28 million, rising to 3.30 million at the end of 42 days, a distinctly submaximal response. In Case II the initial count is given as 0.91 million, rising to 2.1 million on the sixth day, but reaching only 2.45 million on the thirty-second day. In Case III the erythrocytes rose from 1.24 million to 1.4 million in 9 days. In Case IV the erythrocytes rose from 1.19 to 1.42 million in 10 days. These data, it seems to us, though indicating some therapeutic activity, are similar to the responses induced by our primary factor, in the absence of 
the accessory factors (Figures 2 and 3). It has already been pointed out that the material of Laland and Klem shows certain chemical similarities to our Fraction I, derived from the primary factors, Fractions $\mathrm{E}$ or $\mathrm{H}(6)$.

\section{SUMMARY AND CONCLUSIONS}

Studies of the therapeutic activity of purified liver extract in pernicious anemia suggest that the hematopoietic effect may be exerted by an augmentative action of at least three chemically distinct accessory factors upon the activity of a primary factor. Of the three known accessory factors one is $l$-tyrosine, another contains a complex purine, and the third is a peptide. The accessory factors are completely devoid of the primary factor, and without the addition of the primary factor are therapeutically inert. The primary factor has been studied in an amorphous state. Its chemical nature is undetermined. Without the addition of the three accessory factors the primary factor is therapeutically only slightly active.

The authors gratefully acknowledge the cooperation of many physicians in making this study possible. Our special thanks are due to Dr. H. L. Blumgart and to Dr. A. V. Bock of Boston for their placing of patients at our disposal; to Dr. E. P. Joslin of the New England Deaconess Hospital, to Dr. C. S. Westcott and Dr. H. A. Lawson of the Rhode Island Hospital, and to Dr. W. B. Castle of the Thorndike Memorial Laboratory of the Boston City Hospital, for permitting observations on patients at their institutions; and to Dr. Paul Reznikoff of the New York Hospital and to Dr. J. H. Lawrence of the Strong Memorial Hospital, Rochester, N. Y., for kindly carrying out experiments. Drs. George R. Minot and William B. Castle have made many helpful suggestions during the course of the work and in the preparation of the manuscript. The authors are also indebted to Miss Ruth Sullivan and to Miss Jane Bryant for careful technical assistance.

\section{BIBLIOGRAPHY}

1. Fiske, C. H., Subbarow, Y., and Jacobson, B. M., The multiple nature of the pernicious anemia principle in liver. J. Clin. Invest., 1935, 14, 709.

2. Cohn, E. J., Minot, G. R., Fulton, J. F., Ulrichs, H. F., Sargent, F. C., Weare, J. H., and Murphy, W. $P$. . The nature of the material in liver effective in pernicious anemia. I. J. Biol. Chem. (Proc.), 1927, 74, 1xix.

3. Subbarow, Y., Jacobson, B. M., and Fiske, C. H., The separation of the substances in liver which are reticulocytogenic in the guinea pig and which are therapeutically effective in experimental canine black tongue. New England J. Med., 1935, 212, 663.

4. Subbarow, Y., Jacobson, B. M., and Fiske, C. H., A partially purified liver extract therapeutically effective in pernicious anemia. New England $J$. Med., 1936, 214, 194.

5. Subbarow, Y., and Jacobson, B. M., Chemical studies of the pernicious anemia principle in liver. J. Biol. Chem. (Proc.), 1936, 114, cii.

6. Subbarow, Y., Jacobson, B. M., and Prochownick, V., Studies of the pernicious anemia principle in liver. III. The isolation and properties of a substance with primary therapeutic activity. J. Am. Chem. Soc., 1936, 58, 2234.

7. Murphy, W. P., Treatment of pernicious anemia with intramuscular injections of a highly concentrated solution of liver extract. Am. J. M. Sc., 1936, $191,597$.

8. Minot, G. R., and Castle, W. B., The interpretation of reticulocyte reactions: their value in determining the potency of therapeutic materials, especially in pernicious anemia. Lancet, 1935, 2, 319.

9. Dakin, H. D., Ungley, C. C., and West, R., Further observations on the chemical nature of a hematopoietic substance occurring in liver. J. Biol. Chem., 1936, 115, 771.

10. Strandell, B., Poulsson, L., and Schartum-Hansen, $\mathrm{H}$., Experiments to isolate the antianemic principle of the liver. Clinical part. Acta med. Scandinav., 1936, 88, 624.

11. Laland, P., and Klem, A., Experiments to isolate the antianemic principle of the liver. Chemical part. Acta med. Scandinav., 1936, 88, 620.

12. Peters, J. P., and Van Slyke, D. D., Quantitative Clinical Chemistry. II. Methods. Williams and Wilkins Co., Baltimore, 1932. 